\title{
Socio-cultural determinants of criminal and anti-social behaviour of Agaba groups In Calabar Metropolis, Nigeria
}

\author{
Ikoh, Moses U. ${ }^{1}$, Agba, A. M.Ogaboh ${ }^{2}$, and Nwosu, U. Wilson ${ }^{3}$ \\ ${ }^{1}$ Department of Sociology, University of Jos, Nigeria. \\ ${ }^{2}$ Department of Sociology, University of Calabar, \\ Calabar, Nigeria, \\ ${ }^{3}$ IPPA, University of Calabar, Calabar, Nigeria.
}

\begin{abstract}
This paper explored the involvement and arrest of street boys (popularly called Agaba boys) in 19 criminal and anti-social behaviours. Using the General Strain Theory (GST) to guide discussion, the study administered questionnaires on 80 Agaba members drawn purposively from four groups in Calabar Metropolis. It equally held Focus Group Discussions (FGDs) with group leaders. Chi square statistical tool and multiple regressions were used in analysis. The results revealed differences in the four groups' involvements in the 19 criminal and anti-social behaviours that were tested. Socio-economic activities found in their residential areas were the major determinants of type of criminal and anti-social activities they specialized in. The study argues that socio-demographic backgrounds that the boys found themselves exerted significant effect on their subsequent behaviours. It suggests the creation of a Public Private Partnership (PPP) initiative that would deliberately create employments which require low and manual skills that could help in taking most of the boys from the streets.
\end{abstract}

Keywords: Socio-cultural, Criminal Behaviour, Anti-Social Behaviour

\section{INTRODUCTION}

The formation of social group, which is a collection of people who share same characteristics, interact with one another and have some feeling of unity, (Thio, 1989), is not new. What is new apparently is the extent to which socio-cultural groups have metamorphosed into criminal and violent gangs in many Nigerian cities. In recent years the number of reported violence associated with such socio-cultural groups has increased as well as the number of reported crimes. Each major city in Nigeria has its own story to tell about violence and criminality.

A cursory look at those behind violence in Nigerian cities is given by Zakzaky (2001:39). According to him, "most of those who carry out violent crime associated with lootings and killings are groups of jobless youths, who have no means of livelihood". A good number of them are on the streets, unemployed, underutilized and poor, who often attempt to use their youthful vigour negatively (Ezereonwu, 2001).

Calabar, Nigeria's 'Paradise City' has its own share of street boys called 'Agaba Boys'. The boys derive their name from a masquerade called 'Agaba', known for its entertainment through drumming and songs. The metamorphosis of this socio-cultural group to a criminal counter culture is yet to be fully explored. Agaba boys have recently taken to organized violence which has sent scores of the youths to early graves, while many traders are still counting their loses. In 1998, for instance, violent clashes between the leaders of Agaba groups at Ikot Ekpo resulted in the looting of shops and trading stores located along Mount Zion and Atamunu Streets. In March, 1999, the Henshaw town Agaba group and the Base Side group clashed at the Hawkins Cemetery during the burial rites of a rival group member. Several people were attacked with axes and matchets. Windshields of vehicles were smashed and shops located in the vicinity were looted. A youth leader of Henshaw town, lost his life. One of the oldest high schools located in an Agaba territory, Duke Town secondary school, had to close for three days to save the lives of students and teachers from the rampaging gang members (Etim, 2001). In June 2001, the Chairman of Calabar South Local Government had to declare a dust to dawn curfew in the area for two days because of the Agaba boys uprising in Anantigha, 
The malevolent character of Agaba groups and the destructive goals of their members, as revealed by the atrocity unleashed on innocent members of the public have become a source of fear and uncertainty in the town which was once noted for serenity and relaxation. These atrocities are not only increasing in proportion but are lethally more devastated and sophisticated in organization. Report of dastard acts such as looting, killing, maiming, raping, acid bathing, thuggery, property destruction and stealing have become more rampant among Agaba groups in the city. There is hardly any criminal activity in Calabar Metropolis that is not linked to the nefarious activities of the Agaba groups. If they do not stage a combat with a rival group to create pandemonium so that they can loot and vandalize peoples' property, they engage in outright stealing (Ikoh, 2002).

At the last count, eight Agaba groups were identified in Calabar Metropolis, viz; Ikot Ekpo, Etak Udari, Nsidung, Base Side, Anantigha, Idang, White House and Nung Ekpo, (Ikoh, 2002). Available police statistics suggest a strong association between these groups and violence associated with criminal activities in the city. In spite of this, criminological research that focuses on the activities of these groups does not exist. Available Police data lump all street boys apprehended for violence and other criminal offences together with other offenders without disaggregating them. This generates difficulties in answering important questions that could help to probe into the types of crime committed by the different Agaba groups. Equally, the socioeconomic background of these boys has not been examined. This paper intends to fill this gap.

The paper uses the General Strain Theory (GST) that sheds light on the association between socio-cultural and economic strain and criminal behaviour. We hypothesize that Agaba boys face a lot of strain which could not be resolved through merely entertaining the public with their rhythmic songs. Entertainment therefore becomes a camouflage that draws youths into crime and other anti-social behaviours.

Background of Study: Calabar is the capital of Cross River State of Nigeria. It is located at Latitude 04058 "N and Longitude 08012 "E on the Calabar River (Chima \& Inah, (2008). It has a population of 371,022 which grows at the rate of 2.5 per cent (NPC, 2006). The city which is developed from an ancient slave port (Noah, 1978) was Nigeria's National Capital between 1901 - 1906 (Chima \&
Inah, 2008; Udoh, 1970). The indigenous population consists of the Efik, Qua and Efut.

A remarkable demographic shift that changed the complexion of Calabar was noticed after the civil war in 1970. Its status then as the capital of South Eastern State of Nigeria and the commercial nerve center had attracted many people who needed jobs in Government Ministries, Parastatals and commercial houses. Able-bodied men and women abandoned their villages, farms and community life in search of greener pastures in the Metropolis. Unfortunately, the flood of the rural-urban migrants was to exceed the city's economic progress and the provision of jobs, housing and other amenities. Economic growth prompted by petroleum economy had failed to generate commensurate number of jobs for the immigrants. But the immigrants who have decided to trade off rural poverty for urban misery continued to endure in the face of unemployment and underemployment (Ekpenyong, 1989). As a consequence, the population of Calabar swelled and the city became more congested.

Two things confronted the early immigrants in the city; namely, shelter and food. The suburbs of $\mathrm{lkot}$ Ekpo, Etak Udari, Nsidung, Base Side, Anangtiha, Idang, White House and Nung Ekpo provided the needed conveniences. House rents were affordable and local foodstuffs were cheap. The employed consisted of skilled and unskilled workers. The unemployed consisted of jobless youths and the chronically unemployed dependants. Till today these areas provide accommodation for people of low socio-economic status. Most of them live in run down buildings, deteriorating apartments, thatched with shabby rooms. These are where Agaba groups have formations.

The early history of Agaba in Calabar is the history of cultural diffusionism. Originally, an Igbo culture, it was modified by the youth for entertainment during festivities in the Metropolis. Each group used to bring its own Agaba masquerade to the city center to entertain spectators. Competition for territories and supremacy resulted in the acquisition of not only entertaining drums, but also the acquisition of weapons like jack-knives, swords and guns. It became common features seeing one group of Agaba staging a street fight against another group using dangerous dangerous weapons. Each Agaba group viewed the other with suspicion and tried to prevent extension of operational areas of influence. Members who fought more gallantly to maintain the honour of the group became leaders automatically. 
Inflicting pains and injuries against the opponents became a mark of power and prestige.

The need to carry out a reprisal attack against opposing group result in a feud such as reported by Evans-Pritchard among the Neur Tribe of Sudan. The feud never ends. Once an attack is carried out against a rival group, there is always a reprisal attack which often results in the killing of members of rival group. A reprisal attack comes whenever opportunity allows, whether at night or during the day. In some situations, a group may be entertaining at a function, and once information gets to the rival group, the members would mobilize for revenge. Such revenge missions often result in Police intervention and arrests.

Overtime people have stopped inviting Agaba groups to entertain during local gatherings. The Police have also stigmatized them as trouble makers which resulted in outright banning of the groups from displaying during festivities. This development fundamentally altered the original mission of Agaba as entertaining group. Members went underground and resorted to clandestine meetings, where they perfect strategies on how to earn a living, by pickpocketing and snatching of bags and mobile phones from passers-bye. Owing to their criminal counterculture activities, Agaba members have no sense of belonging among family members and immediate neighbours. They make their abode at locations considered unusually removed and bizarre for human habitation. For instance, the Agaba members at Nsidung called Nsidung Boys prefer to stay inside Hawkins Cemetery where they attack and rob members of the public. The Idang boys stay on the Creeks of Calabar River. They escape police arrest by ferrying into the Creeks, after committing a crime. Agaba members have thus degenerated into hordes of criminals.

Today, Agaba culture is expressed in insatiable appetite for drinking, smoking of Indian hemp, and rape. Members live at extra residential locales with continued affiliation based on self defined inclusion criteria. Wherever one group lives, such an area becomes their zone and capital. No other group has occupancy and occupational rights there. Acts of trespass is an open invitation for war, and warfare is the past time of Agaba boys. This cohort living enables frequent interaction among members and the forging of common counter-culture identity. What began as a socio-cultural group for entertainment, gradually moved to pick-pocketing, bullying, raping and thuggery and has in recent times graduated to convenience robbery gangs. Agaba's fame in entertainment during festivities has gradually been replaced by notoriety in crime. Its members continue to operate with so much confidence and deep seated disrespect for law and order in the Metropolis. Their activities seem to be exacerbated by hemp smoking and uncontrollable drug use.

Theoretical consideration: Empirical findings suggest that youngsters who are similarly constrained often find a purpose in group formation; they use such platform to reject middle class values, but rather establish their own values to fulfill their goals (Shorts \& Strodtbeck, 1974). Such counter culture conflicts with that of the dominant culture. The General Strain Theory (Agnew, 1992) seeks to offer explanation for the development of criminal subculture out of such counter-cultural group formation. He listed the strains that accompany criminal sub-culture to include failure to achieve positively valued goals; the increasing frequency of negative or adverse stimuli; and the lost of positively valued stimuli.

The first source of strain, failure to achieve positively valued goals incorporates Merton's (1938) argument that crime is the result of a discrepancy between economic aspiration and expectation. Merton asserted that monetary aspiration combined with an unequal distribution of legitimate opportunities might produce criminal tendencies. For instance, poor educational qualification of Agaba members often constrained them from getting jobs with attractive pay packets. Some boys have little or no access to conventional and legitimate means of livelihood. Such goal blockage results in rejecting the success goals of the mainstream structure and replacing them with alternative set of norms from which they can achieve ingroup goal or success. Thus criminal subculture becomes not so much a culture of achieving success in terms of mainstream goals but also valued activity to which are attached glory, prowess and profound satisfaction. Monetary aspirations combined with an unequal distribution of legitimate opportunities might result in three possible responses: criminality, conflict and retreatistism (Adler, et al, 1995).

Another source of strain is exposure to adverse situation and experiences, which tend to disproportionately affect individuals in disadvantaged communities. Negative stimuli such as economic deprivation and family disruption increase the likelihood that individual would experience negative emotions such as frustration to anger (Agnew, 1992). 
Crime occurs when people think that there is no need to adopt constructive means to reach their goals and believe that legitimate opportunities to reduce their deprivation cannot be attained or are unavailable to them. In developing countries, "demonstrating effect" leads to a desire for a better standard of living among people who moved to large cities where wealthy life style can be observed first hand (Sampson, 1985). Cities may not cause or produce crime or urban violence, but social discord, which is created by a huge contrast in economic well-being can. Large scale economic marginalization of the youths can push them into armed robbery and other vices in the city (Ekpenyong, 1999; Agekameh, 2001).

Similarly, the absence of positive stimuli such as the loss of parents, family member, and rejection by any of the parents or loved ones can adversely affect the psychological state of the individuals. When people respond to strain with anger, while at the same time externalizing the blame and anchoring on significant others with criminal values, the chances for instrumental (e.g. engaging in lucrative crime) or retaliatory (e.g. engaging in violent crime) type of crime increases.

\section{METHODOLOGY:}

From the eight Agaba groups identified in Calabar Metropolis, purposive sampling was used to select four of them for study. These include Nsidung, Base Side, Idang and Etak Udari. The study administered 80 questionnaires on Agaba members (20 from each of the 4 Agaba groups). The 20 respondents from each group were also purposively picked during a general meeting held on the researchers' request. We wanted members that have been actively participating in the groups' activities. For that reason each group leader was requested to identify active members for the administration of questionnaire. Such technique was most appropriate because of the need to use sample that could best represent the population of study.

The study used survey method. A combination of structured questionnaire and Focus Group Discussions (FGDs) were used to obtain data from respondents. Carefully standardized questionnaire influenced by the variables highlighted in the guiding theory were used. Short and Strodtbeck (1974) used 15 labels to develop questions which tested the socio-economic characteristics that expose streetgang members to conflict, criminal and retreatist subcultures. These labels were adapted and modified into our questionnaire. Other questions motivated by our discussions and interactions with the Agaba boys sought to measure subculture of violent scale and their personal values. Respondents were asked whether they approved non-aggressive responses to some type of provocation. Discussions ranged from Agaba groups' members involvement in crime, to their attitude toward sister Agaba groups.

The questions were constructed to measure both the dependent and independent variables. The dependent variables were involvement in and / or arrest for a given crime and anti - social behaviours. We categorized these criminal tendencies into nineteen varieties of behaviour frowned at by the society as criminal and definitely undesirable. These include, Alcohol (drinking), Indian hemp (smoking), narcotic (sniffing, injecting), gang fighting, individual fighting, assault, theft, burglary, robbery, thuggery, extortion, rape, pimping, collection of illegal tolls, pilfering on passengers items, borrowing, begging for money, hanging on the street and pick-pocketing. In other to specify and measure the dependent variable(s) for each crime, we asked questions about respondents' involvement and police arrest. Involvement and / or arrest were coded as 1; noninvolvement was, coded as zero. Both involvements and arrests for a particular crime were treated as functions of socio-demographic influence including 'family living structure', 'parental control', 'age', 'educational attainment', 'ethnic groups', 'parental occupation' and 'deceased parents'.

Family living pattern was measured by three dummy variables. Equally the parental control structure which sought to know whether the respondents' parents knew the activities of the respondents once they were outside the home employed three dummy variables. Age was measured in a continuous form. The percentage of respondents with less than schoolcertificate-attempted was scored zero, and the percentage above school-certificate-attempted was scored one. Ethnic group of respondents was measured by four dummy variables. These were 1 each for Efik, Efut, Qua and Immigrants (Nonindigene). In order to identify the indigenes from the non-indigenes, we asked respondents to mention the native language of their fathers. Parental occupation was measured by seven dummy variables, while deceased parents had three dummy variables, one each for 'mother died', 'father died', and 'both parent died'.

Chi-Sqaure analyses were used to test Agaba groups' differences with respect to sociodemographic variables as well as involvement in 
criminal and anti-social behaviours. In addition, a logistic regression model was constructed first, to test the likelihood of arrest for criminal and anti-social behaviours as a result of those involvements, and second, to predict the effect of socio-demographic backgrounds on the arrests. Background information including age, parental control, living pattern, deceased parents, educational attainments, ethnic group and family control were simultaneously entered into the model along with the respondents' rating for nineteen criminal and anti-social behaviours. Four separate logistic regression analyses each for Nsidung, Base Side, Idang and Etak Udari Agaba groups, were also constructed to examine the odds of arrest as a result of involvement and the effect of the socio-demographic backgrounds of the respondents.

Logistic regression commonly called logit regression is used when the dependent variable (response variable) is dichotomous (i.e binary or $1-0$ ). The dependent variables may be quantitative, categorical or mixture of the two. We reported involvement and arrest for criminal and antisocial behaviours in the form of an odds ratio (OR). An odds ratio greater than 1 indicates that the odds of involvement in a criminal activity as well as police arrest for the offence are higher. An odd ratio of less than 1 has the opposite interpretation (Bowers, House \& Owens, 2003). A 95 per cent confidence interval $(\mathrm{Cl})$ was computed for each ratio (OR). A confidence interval containing 1 suggests that the odds ratio is not significantly different from 1, thus indicating no statistically significant level. The statistical significance was put at $p<0.05$ using the t-test, defined here as the ratio of the parameter estimate to its corresponding asymptotic standard error.

\section{RESULT}

Socio-Demographic Characteristic: Table one presents the socio-demographic characteristics of the respondents. The mean age of the respondents was $19.3(\mathrm{SD})=4.39$ for Nsidung group, $18.1(\mathrm{SD})=4.25$ for Base side group, 20.05 (SD) $=4.47$ for Idang group and $17.8(\mathrm{SD})=4.21$ for Etak Udari group. Many of the parents at Nsidung $(\mathrm{N}=8,40 \%)$ and Idang $(\mathrm{N}=10,50 \%)$ were farmers. This suggests the utilization of the abundant land in the area for urban agriculture. But other than farming, the beach at Nsidung which attracts economic activities in fishing and ship loading encourages trading and motor cycle transportation in similar proportion $(\mathrm{N}=3,15 \%)$.
Etak Udari which is situated in close proximity to the popular Etim Edem Motor Park and market encourages parental occupation in trading $(\mathrm{N}=5$, $25 \%)$, motor cycling $(\mathrm{N}=3.15 \%$ and labourer $(\mathrm{N}=2$, $10 \%)$. The Base Side beach equally influences parental occupation in either fishing, fishing net repairs or cutting of firewood, classified here under 'other occupations' ( $\mathrm{N}=7,35 \%)$. Other than these, trading $(\mathrm{N}=4,20 \%)$ and manual labour $(\mathrm{N}=3,15 \%)$ were sources of livelihood. There was no significant difference in parental occupation among the groups, $[X 2,18(\mathrm{~N}=80)=20.68, \mathrm{P}=0.05]$.

There was equally no significant difference in the living pattern of respondents $[X 2,6(\mathrm{~N}=80)=4.96, \mathrm{P}=$ 0.05]. Most of the respondents across the four studied groups lived with their parents, including foster parents. At Etak Udari, a half of the respondents had no parents, while a majority of the respondents at Nsidung reported of either the dead of their mother, fathers or both parents. A higher proportion of Agaba members, especially at Base Side and Etak Udari were non-indigenes $(\mathrm{N}=11$, $55 \%)$ and $(\mathrm{N}=13,65 \%)$ respectively. In terms of family control, majority of the parents across the groups did not know their children's where about once they were out of the home. The differences across the group were not significant $[X 2,6(N=80)$ $=7.93, P=0.05]$, with many parents at Etak Udari 'not caring' at all to know the children's where about.

Involvement in Criminal and Anti-Social Behaviours: Chi-square results of Agaba Boys' involvement in 19 criminal and anti-social behaviours are reported in table 2 . A significant group differences was reported in excessive drinking of alcohol $[X 2,3$ $(\mathrm{N}=80)=14.94), \mathrm{P}=0.002]$. More boys at Etak Udari $(80 \%)$ and Nsidung $(70 \%)$ than in Base Side (45\%) and Idang (10\%) reported of their involvement in excessive alcohol drinking. There was however no significant group differences when it comes to the smoking of Indian hemp (marijuana) [X2, 3(N=80) $=4.56, P=0.206]$ and sniffing/injecting of narcotic $[X 2$, $3(N=80)=3.95, P=0.267]$. Similarly, there was no significant differences in gang fighting among the groups, $[X 2,3 \quad(N=80)=2.04, P=0.564]$. The groups significantly differed when individual fighting was tested $[\mathrm{X} 2,3(\mathrm{~N}=80)=10.01, \mathrm{P}=0.019]$. 
Am. J. Sci. Ind. Res., 2010, 1(3): 380-391

Table 1. Socio-demographic characteristics of respondents.

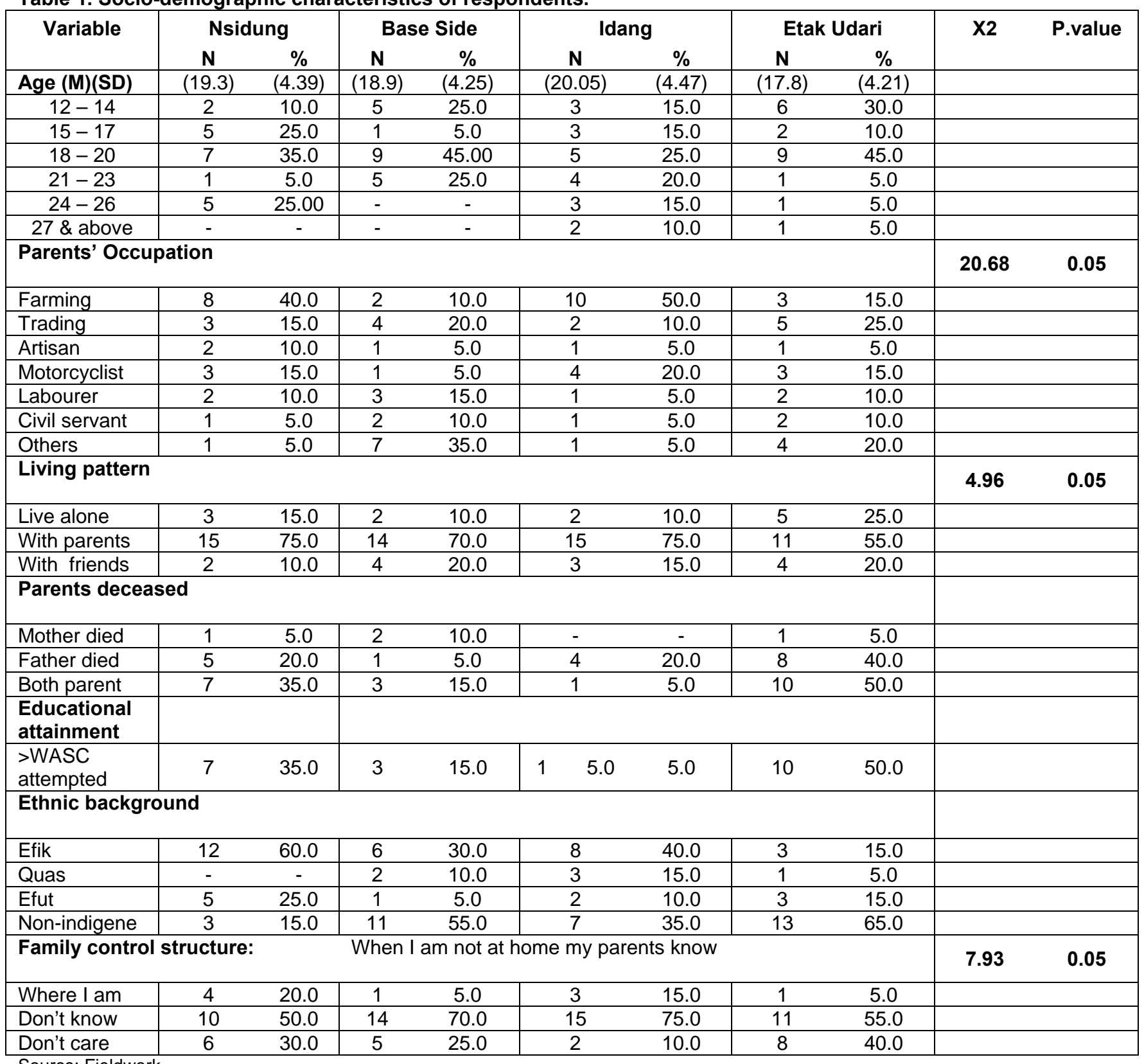

Source: Fieldwork

When involvement in assaults was analysed, nonsignificant group differences were found, $[X 2,3$ $(\mathrm{N}=80)=4.38, \mathrm{P}=0.224]$. Subsequent analyses revealed that differences of the boys involvement in theft, burglary, thuggery and extortion were not significant $[X 2,3 \quad(\mathrm{~N}=80)=3.33, \mathrm{P}=0.343], \quad[\mathrm{X} 2,3$ $(\mathrm{N}=80)=1.07, \mathrm{P}=0.785], \quad[\mathrm{X} 2,3 \quad(\mathrm{~N}=80)=5.71), \mathrm{P}=$ 0.0.126], $[X 2,3(\mathrm{~N}=80)=5.49, \mathrm{P}=0.0 .134]$, and $[\mathrm{X} 2,3$ $(\mathrm{N}=80)=2.48, \mathrm{P}=0.478$ respectively. The analyses of the boys involvement in rape indicated that Base
Side and Idang were more significantly likely than either Nsidung and Etak Udari to involve in raping women $[X 2,3(\mathrm{~N}=80)=11.53), \mathrm{P}=0.009]$. Significant group differences existed with regards to involvement in pimping $[X 2,3(\mathrm{~N}=80)=117.40), \mathrm{P}=0.000]$.

Base Side boys (80\%), followed by Nsidung (75\%) and Etak Udari boys (70\%) were more likely than Idang boys $(15 \%)$ to involve in pilfering $[X 2,3(\mathrm{~N}=80)$ $=22.92, P=0.000]$. This result suggests that passengers that patronized ferries at the Base side 
and Nsidung beaches and the Etim Edem Motor Park, which lies at the vicinity of Etak Udari most often have their goods and luggage pilfered. There were significant differences in involvement in borrowing $[X 2,3(\mathrm{~N}=80)=7.62, \mathrm{P}=0.054]$. But begging for money, and 'hanging' at street corners were not significant $[X 2,3(\mathrm{~N}=80)=2.58, P=0.460]$ and $[X 2$, $3(\mathrm{~N}=80)=6.22, \mathrm{P}=0.101]$ respectively. Further analyses indicated that Etak Udari Boys (90\%) and Base Side Boys (55\%) more than Nsidung (45\%) and Idang (30\%) reported significant involvement in pickpocketing $[\mathrm{x} 2(3, \mathrm{~N}=80)=15.76, \mathrm{P}=0.001]$. Nearness to the busy markets may have made pickpocketing a rewarding crime for the Boys.

Arrest for Criminal and Anti-social Behaviours: The results of the logistic regression analyses predicting the odds of arrest as a result of involvement in criminal and anti-social behaviours and the effect of socio-demographic backgrounds are presented in Table 3. Age, parental occupation, living pattern, deceased parents, educational attainment, ethnic group and family control are shown as control variables. The statistical significance $(P<.05)$ of the odds ratio for each covariate category relative to the reference group is provided.

Table 2. Chi-square result of involvement in 19 Criminal and anti-social behaviours by Agaba boys in Calabar Metropolis,

\begin{tabular}{|c|c|c|c|c|c|c|}
\hline Variables & $\begin{array}{c}\text { Nsidung } \\
\mathrm{N}=20\end{array}$ & $\begin{array}{c}\text { Base Side } \\
\quad \mathbf{N}=\mathbf{2 0}\end{array}$ & $\begin{array}{l}\text { Idang } \\
\mathrm{N}=20\end{array}$ & $\begin{array}{c}\text { Etak Udari } \\
\qquad \mathbf{N}=\mathbf{2 0}\end{array}$ & $\mathrm{X} 2$ & P.Value \\
\hline Excess alcohol & $14 / 20(70)$ & $9 / 20(45)$ & 6/20 (30) & $17 / 20(80)$ & 14.94 & 0.002 \\
\hline Indian hemp & $17 / 20(85)$ & $13 / 20(65)$ & $11 / 20(55)$ & $16 / 20(80)$ & 4.56 & 0.206 \\
\hline Narcotic & $8 / 20(40)$ & $11 / 20(55)$ & $7 / 20$ (35) & $13 / 20(25)$ & 3.95 & 0.267 \\
\hline Gang fighting & $12 / 20(60)$ & $14 / 20(70)$ & $16 / 20(80)$ & $13 / 20(65)$ & 2.04 & 0.564 \\
\hline Individual fighting & $7 / 20$ (35) & $5 / 20(25)$ & $3 / 20(15)$ & $12 / 20(60)$ & 10.01 & 0.019 \\
\hline Assault & $18 / 20(90)$ & $17 / 20(85)$ & $16 / 20(80)$ & $13 / 20(65)$ & 4.38 & 0.224 \\
\hline Theft1 & $13 / 20(65)$ & $132 / 0(60)$ & $14 / 20(70)$ & $17 / 20(85)$ & 3.33 & 0.343 \\
\hline Burglary & $12 / 20(60)$ & $14 / 20(70)$ & $11 / 20(55)$ & $13 / 20(65)$ & 1.07 & 0.785 \\
\hline Robbery & 2/20 (10) & $6 / 20(30)$ & $8 / 20(40)$ & $8 / 20(40)$ & 5.71 & 0.126 \\
\hline Thuggery & $17 / 20(85)$ & $19 / 20(95)$ & $18 / 20(90)$ & $14 / 20(70)$ & 5.49 & 0.139 \\
\hline Extortion & $18 / 20(90)$ & $18 / 20(90)$ & $15 / 20(75)$ & $16 / 20(80)$ & 2.48 & 0.478 \\
\hline Rape & $9 / 20(45)$ & $17 / 20(85)$ & $12 / 20(60)$ & $7 / 20(35)$ & 11.53 & 0.009 \\
\hline Pimpimg & 6/20 (30) & $3 / 20(15)$ & $12 / 20(60)$ & $1 / 20(5)$ & 17.30 & 0.000 \\
\hline Illegal toll coll. & $17 / 20(85)$ & $18 / 20(90)$ & $13 / 20(65)$ & $7 / 20$ (35) & 17.40 & 0.000 \\
\hline Borrowing & $18 / 20(75)$ & $17 / 20(85)$ & $13 / 29(65)$ & $7 / 20$ (35) & 7.62 & 0.054 \\
\hline Begging money & $16 / 20(80)$ & $13 / 20(65)$ & $17 / 20(85)$ & 16/20 (80) & 2.58 & 0.460 \\
\hline Hanging & $11 / 20(55)$ & $10 / 20(50)$ & $13 / 20(65)$ & 17/20 (85) & 6.22 & 0.101 \\
\hline Pick pocket & $9 / 20(45)$ & $11 / 20(55)$ & $6 / 20(30)$ & $18 / 20(90)$ & 15.76 & 0.001 \\
\hline
\end{tabular}

${ }^{*} \mathrm{P}<0.05 \mathrm{~N}=80$

Source: Fieldwork

Indian hemp smoking more than drinking excessive alcohol appeared to be a significant predictor of arrest across the four groups. The odds of arrest for smoking Indian hemp was about four times higher in Etak Udari, and three times higher in Nsidung and Base Side, when compared to arrest for drinking excessive alcohol. Arrest for reason of involvements in narcotic among the group was not significant. However arrest for gang fighting among the group was significant. Idang Boys were five times more likely to be arrested for gang fighting than in excessive drinking of alcohol $(\mathrm{OR}=5.03, \mathrm{Cl}=2.65-$ $2.81)$. this was followed by Base Side $(\mathrm{OR}=4.17, \mathrm{Cl}$ $2.14-3.03)$ and Nsidung, $(\mathrm{OR}=3.12, \mathrm{Cl}=2.84-$ 4.60). This suggests the generality of ongoing rivalry among the groups. The likelihood of being arrested for gang fighting among Etak Udari Boys however was low $(\mathrm{OR}=1.13, \mathrm{Cl}=1.04-1.36)$. Contrary to expectation arrest for individual fighting was only significant among the Base Side boys, $(\mathrm{OR}=1.83, \mathrm{Cl}$ $=2.84-3.53)$ and Etak Udari Boys (OR $=4.25, \mathrm{Cl}=$ $2.72-2.81$ ), thus suggesting more group cohesion among Nsidung and Idang groups. 
Am. J. Sci. Ind. Res., 2010, 1(3): 380-391

Idang Boys were 5.12 times likely to be arrested for assault than for excessive drinking of alcohol (OR = $5.12, \mathrm{Cl}=3.13-4.76)$ and 3.45 times for theft (OR = $3.45, \mathrm{Cl}=2.21-2.47$ ). Nsidung Boys' odds of arrest for assault were 3.45 times higher than the arrest for drinking excessive alcohol. Among the Base Side Boys, arrest for assault (OR $=4.66, \mathrm{Cl}=2.05-2.91$ ) and theft $(\mathrm{OR}=0.81, \mathrm{Cl}=2.04-2.59)$ were significant.

The odds of arrest for burglary were 94 per cent [(OR - 1)*] higher among Etak Udari Boys $(\mathrm{OR}=1.94, \mathrm{Cl}$ $=0.74-1.25)$. The odds of being arrested for burglary among the Nsidung Boys were not significantly different from the odds of being arrested for excessive alcohol drinking. When robbery was examined, the findings showed that Idang boys had 1.27 times the odds of being arrested $(\mathrm{OR}=1.27, \mathrm{Cl}$ $=0.83=1.86$ ) while Base Side recorded the odds of 1.09 times $(\mathrm{OR}=1.09, \mathrm{Cl}=0.41=1.23)$ and Etak Udari 1.08 times of being arrested.

The results of extortion were mixed. While the odds of arrest among Based Side Boys, Nsidung Boys and Idang were significant $(\mathrm{OR}=2.19, \mathrm{Cl}=2.06-3.01)$, $(\mathrm{OR}=1.63, \mathrm{Cl}=1.15-2.13)$ and $(\mathrm{OR}=1.59, \mathrm{Cl}=$ $1.52-1.84)$ respectively, the odds of being arrested for extortion in Etak Udari was not significantly different from being arrested for excessive drinking of alcohol. For thuggery, the biggest odds of arrest was recorded among the Base Side Boys, $(\mathrm{OR}=5.13, \mathrm{Cl}$ $=2.44-2.91)$, followed by Etak Udari, $(\mathrm{OR}=5.02, \mathrm{Cl}$ $=3.04-4.60)$ and Idang, $(\mathrm{OR}=4.43, \mathrm{Cl}=2.70-$ 2.97). Similarly, the odds of arrest for thuggery among the Nsidung group was high, about 4 times when compared to the odds of being arrested for excessive drinking of alcohol.

The odds of arrest for rape were significantly higher among Nsidung Boys, $(\mathrm{OR}=1.98, \mathrm{Cl}=3.43-4.99)$. Although Base Side and Idang boys had 1.15 times and 1.97 times respectively, the odds of being arrested for rape, the odds were not significant within the 95 per cent confidence interval. Idang Boys were 1.24 times as likely to be arrested for pimping when compared to the likelihood of being arrested for drinking excessive alcohol. Etak Udari boys recorded the odds of arrest that was 53 per cent higher than the arrest for drinking excessive alcohol, while the arrest among Nsidung Boys for pimping was quite negligible, $(\mathrm{OR}=0.06, \mathrm{Cl}=0.14-1.64)$. The odds of being arrested for illegal toll collection was higher at Base Side (OR $=1.21, \mathrm{Cl}=0.52-1.03$ ) and Idang (OR 1.02, $\mathrm{Cl}=0.71-1.49$ ) than elsewhere; just as the odds of being arrested for pilfering were significantly elevated among Nsidung, Base Side and
Etak Udari groups. While Etak Udari Boys were 189 per cent more likely to be arrested for pilfering, (OR = $2.89, \mathrm{Cl}=1.84-2.50$ ), Base Side Boys were about 2.14 times as likely to be arrested for similar offence, $(\mathrm{OR}=2.14, \mathrm{Cl}-2.17$ - 2.56). Nsidung Boys had arrest odds of 1.09 times higher for pilfering than in excessive drinking of alcohol.

The odds of arrest for borrowing money were not significant among the groups, and were negligible among Nsidung Boys when compared to the likelihood of being arrested for excessive drinking of alcohol. Following similar pattern, the odds of arrest for begging for money were in the negative direction among the groups. Nsidung Boys were much less likely to be arrested for 'hanging'. This suggests the security of the Hawkins Cemetery where the Boys often hang out. But Idang boys were 54 per cent more likely to be arrested for 'hanging' than for excessive drinking of alcohol. Interestingly, the odds of being arrested for pick pocketing were significant at Nsidung, OR $=3.85, \mathrm{Cl}=2.52-2.94$ ), Base Side, $(\mathrm{OR}=1.35, \mathrm{Cl}=1.53-1.97)$, and Etak Udari $(\mathrm{OR}=$ $1.53, \mathrm{Cl}=1.15-1.90)$.

Effect of Background Characteristics on Arrest: As shown in table 3, age differences were observed in the prevailing odds of arrest for involvement in criminal and antisocial behaviours. Generally, it appeared that the higher the age, the less likely the odds of arrest, except at Etak Udari, where the odds of arrest were 3.21 times higher between the age bracket of $24-26$ years than between the age bracket of $12-14$ years. Parental occupation did not reduce the odds of arrest except among Nsidung Boys where parental occupation of farming reduces the odds of arrest by 7 per cent.

Boys who lived with friends were 3.79 times more likely to be arrested for criminal and antisocial behaviours at Base Side than those who lived with both parents (OR = $3.79, \mathrm{Cl}=3.21-4.47$ ). Nsidung Boys who lived with friends had almost twice the odds of being arrested for criminal offences than their counterparts who lived with their parents. Similarly, boys who lived alone in all the four groups studied had significant odds of being arrested on account of criminal and antisocial behaviours. Boys whose mothers had died were significantly at odds of being arrested for one offence or the other. Being orphaned of a mother therefore, was more likely to produce strains that expose the boys to committing criminal offences than being orphaned of a father. However among the Etak Udari Boys, the dead of a father was more felt than that of a mother. It generated 2.02 times the odds of being arrested for involvement in criminal and antisocial behaviours (OR = $2.02, \mathrm{Cl}=1.64-2.83)$. 
Am. J. Sci. Ind. Res., 2010, 1(3): 380-391

Table 3. Logistic Regression predicting the odds of Arrest and Effect of Socio-demographic variables on crime and antisocial behaviours

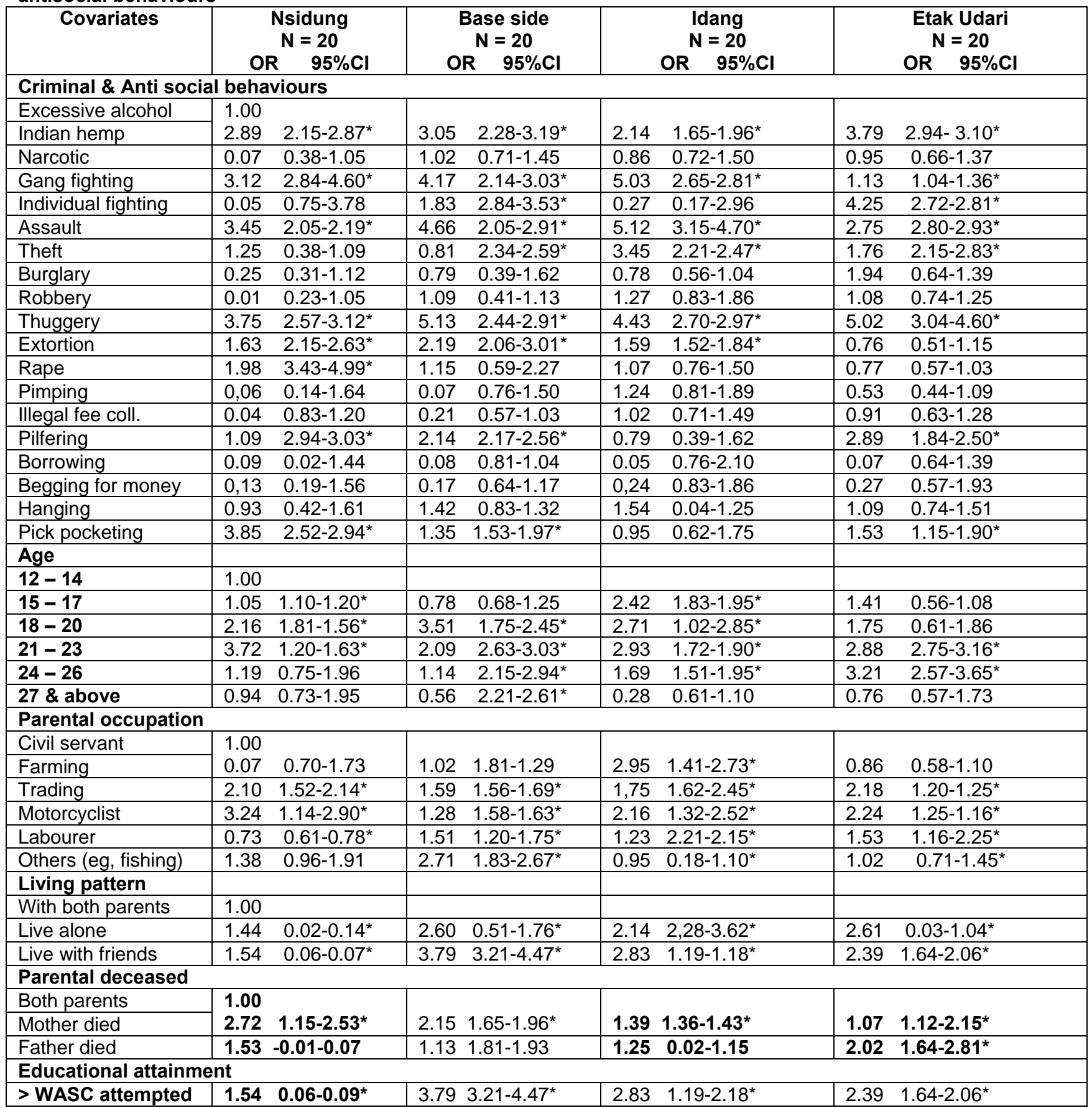

, $N=80$, Source: Fieldwork

Boys who were educated above 'school certificate attempted' were siginificantly more likely to be arrested for criminal and antisocial behaviours at Base Side (OR $=3.74, \mathrm{Cl}=3.21-4.47)$. Similar pattern in the odds of arrest accounted for boys at Idang $(\mathrm{OR}=2.83, \mathrm{Cl}=$ 1.19 - 2.18), Etak Udari, $(\mathrm{OR}=2.39, \mathrm{Cl}=1.64-2.06)$ and Nsidung $\mathrm{OR}=1.54, \mathrm{Cl}=0.06-0.09)$. When ethnic background was considered, analyses showed that ethnicity was not a consideration for arrest. The odds of being arrested for involvement in criminal and anti-social behaviour did not respect ethnic background. Neither parental knowledge of 'where to find a child when he is not at home' nor 'loosing sleep over his where about' was a significant prediction of arrest for criminal and 
antisocial behaviour. However Nsidung Boys whose parents "would not care" about their whereabouts once they left home were 161 per cent likely to be arrested for criminal and antisocial behaviours when compared to those whose parents knew where to find them whenever they were not at home. Lack of parental care and protection was therefore a strong factor in exposure to crime and the consequent arrest.

\section{DISCUSSION}

Nsidung Boys: Chi-square analyses revealed differences in the involvement of the groups in 19 criminals and antisocial behaviours, some of which were significant. Nsidung group was known for its involvement in assault, borrowing, extortion, thuggery, Indian hemp (marijuana) smoking, excessive drinking of alcohol, pilfering and begging for money. Members of the group were significantly more likely to be arrested for pick-pocketing, thuggery, gang fighting, pilfering, rape, extortion, assault, and Indian hemp (marijuana) smoking. For the Boys, possession of thuggery skills appears to be resourcefull especially during electioneering campaigns/elections. Politicians recruit them as body guards. They intimidate and assault political opponents. Although thuggery continues to be a service needed by the Political Godfather, many of the Boys tend to employ their thuggery skills in intimidating and extorting money and other valuables from unsuspecting members of the public after elections. In the absence of politicians' protections, many of them are easily picked up by the police.

'Gang fighting' as opposed to 'individual fighting' suggests unity of purpose among the Nsidung group. But its significant involvement in other criminal and antisocial acts could be explained by a combination of factors. As shown in table 1, although majority of the Nsidung Boys were indigenes, very few of them had parents to look after them. Lack of parenting and poor parenting suggests early life strains (James, 1996). Only 35 per cent of the Boys experienced Senior Secondary School education, which they could not complete. Due to lack of competitive skills for the formal economic sector, subsistence economic activities at the Nsidung beach became main sources of livelihood. It started with the illegal collection of 'landing fees' from fishermen. When the Municipal Government discovered this to be a legitimate source of increasing revenue for the council, the Boys were thrown out of business. They resorted to offloading of canoes and collection of landing duties which they called usin ubok from grayfish traders. Traders who refused to yield to their demands were usually assaulted and / or had their goods pilfered or damaged. Such acts were enhanced by drug use.

In want of boldness and strength, alcohol and marijuana become the necessary agents. At the Hawkins
Cemetery where they often hang out or relax to share they loots, marijuana is not only smoked, but mixed with the locally distilled gin called akai kai to produce a more intoxicating liquid called combine, which most of the Boys take delight in drinking. One of the physiological effects of marijuana smoking is hormonal disorder and anxiety. It contributes to the inability of the Boys to defer gratification and suggests the increasing rape cases among the Boys at Nsidung. In Shorts and Strodtbeck's (1992) analysis, inability to defer gratification can generate a combination of conflict, criminal, and retreatists reactions. Traders who are unable to meet the demands of the Boys may call in the police and / or other security agencies for protection. Such development often resulted in a face off between the Boys and such traders. The existence of such unresolved conflict usually results in revenge missions where these traders would have their goods either outrightly stolen or damaged next time they offload at the beach. This revenge usually continued until the Boys are appeased by the traders.

Base Side Boys: The multiple regression analyses showed that the Base Side boys were more likely to be arrested for crime of thuggery, assault, individual fighting, marijuana smoking, gang fighting and pick pocketing. Their rate of involvement in illegal fee collection, rape, burglary and borrowing, was high. Economic activities at Base Side are enhanced by being 'tough' and 'high'. The labour intensity of ship loading and offloading amplified capacity for getting-by. And being tough and getting the cooperation of peers largely achieves this. The boys succeed in extorting money from passers-bye in the evening and stealing as well as pilfering on travellers' goods. Their appreciation of drugs and marijuana could be explained either as source of power or to dispense with inferiority complex and or suspend their conscience when dealing with a victims

Idang Boys: Apart from involvement in antisocial behaviours like 'hanging' at street corners, begging for money, borrowing and pimping, Idang boys involvement in criminal acts of thuggery, assault, extortion, theft, gang fighting, illegal toll collection and hemp (marijuana) smoking was high. Their odds of arrest for these offences were significant, apart from illegal toll collection. Their nearness to the creeks engendered the cultivation of marijuana for the brewing of 'combine', some quantity of which they sold to members of the public as well as other gang leaders. Illegal toll collection and hemp (marijuana) smoking are commonly seen when the boys blocked road to collect tolls from motorcyclists, welding matchets and knives, under the guise of Ndito edidia nso? (what would the children eat?).

Etak udari: The activities of the boys at Etak Udari are influenced by the location of the Etim Edem Motor Park 
and the existing economic activities of the area. The boys principally capitalize on the booming activities of buying and selling. Their involvement in pick pocketing, hanging at street corners and around the motor park, begging for money, borrowing, pilfering as a way of life received high rating. So also were involvements in excessive alcohol drinking, Indian hemp smoking, gang fighting, theft, assault, burglary, extortion and thuggery. Their odds of being arrested for a number of these criminal activities and anti social behaviours were equally high. The Etim Edem Motor park and Watt Market where Etak Udari Boys often operate are located a few metres away from the Atakpa Police station, from where security operatives often provide surveillance.

Touting developed in the boys some retreatist values that give them 'signifying' label such as exchange of insults and displaying of verbal virtuosity. To successfully discharge the economic function of conveying wares with wheel barrow for traders, they need to be strong and tough. They must also be smart to extort and pilfer on passengers goods. Alcohol consumption and marijuana smoking made them comfortable in such habits.

The observed differences among the groups in involvement and arrest for criminal and antisocial behaviour suggest the influence of their respective environments. The availability of legitimate and illegitimate socio-economic opportunities seems objectively more limited around the areas of Nsidung, Base Side, Idang and Etak Udari. Legitimate socioeconomic opportunities available are in trading, transport, restaurant, hawking, hotel and drinking parlour businesses. Illegitimate businesses are seen in hemp growing and selling, extortion, illegal toll collection, stealing and pilfering on travellers' goods, and looting. Legitimate socio-economic opportunities (outside these areas) in the Metropolis have brought the boys face to face with opportunities they have no skills to fit in. Less than a half of the eighty boys that participated in this study were educated above school certificate attempted, and most of them were orphans. Their lack of saleable skills combined with an equal distribution of legitimate opportunities often result in strain (Agwe, 1992).

Many researchers have demonstrated that strain often results in strong feelings of frustration, disappointment and anger, which could lead individuals to choose illegitimate means to achieve their goals (Paternoster \& Mazerolle, 1994; Cernkovich, Giordano, \& Rudolph, 1989). In the face of inability to either own their own business or get employed in the available economic openings, Agaba boys simply retreat to their original cultural values of being tough, smart, hang, share etcetera, to keep life going. This pervasive exposure to negative stimuli in conjunction with the loss of positively valued stimuli is not without consequences (Blau \& Blau, 1982). It may explain some deliberate street fighting staged by Agaba members inorder to create conducive opportunity to loot. It may also suggest that after all, violence disturbances could be rewarding.

The implications of the findings of this study extend beyond the field of criminology to health. Between the mean ages of 17.8 and 20.05 years, the respondents were already exposed to excessive drinking of alcohol, drugs and marijuana smoking instead of consumption of milk and the storage of calcium in enough quantities to avert the problem of bone decalcification after middle age (Escandon \& Calvez, 2005). Alcohol consumption diminishes milk intake. And it is being consumed on the belief that it gives stability and happiness.

A few minutes after smoking marijuana, the smoker feels a powerful surge of vitality, energy, enthusiasm and satisfaction (Charles, Ikoh, lyamba \& Charles, 2005). However, the smoker equally experiences difficulties in concentration, mental disorder, speech impediment, a decrease in short term memory, sensory alteration, drowsiness, loss of self control and intense yearning for food (Escandon \& Calvez, 2005). The hazards on both psychological and physiological levels have been enumerated. They include disturbances to memory, loss of psychomotor abilities and of mental clarity; the tendency to neglect the fulfillment of ones duty as well as ones physical appearance. Marijuana affects the heart and lung and could result in cancer, impair intellectual development, high risk sexual behaviour and generate greater rate of anomalous behaviours bordering on criminal activities (Alcohol, Anonymous, 2005).

Unfortunately the health risks of Marijuana smokers are not limited to the smokers themselves. Many Agaba members ply the roads in the metropolis as commercial motor cyclists. Empirical finding is yet to establish how many of the motor bike accidents in the metropolis, that have resulted in death, high compounded fractures and permanent disabilities are linked to Agaba-bike riders. Although significant differences exist among the studied groups, in terms of raping, every group had a percentage of involvement. This could be attributed to high consumption of not only excessive alcohol, but also marijuana which motivates high risk sexual behaviours, other than criminal activities.

The multiple regression analyses raised a few additional issues. The incessant blocking of roads to collect illegal toll from unsuspecting members of the public can not be devoid of marijuana influence. The harassment often involved wielding of matchets and knives. Yet despite the involvement of Agaba in road blocking and illegal toll collection, especially at Nsidung, Base Side and Idang, the odds of arrest for those involved have been largely 
negligible. Similarly, arrest for burglary and robbery, especially convenience robbery was not significant.

A roadmap out of strain that often elevated the chances for criminal behaviour of the utilitarian nature have severally been suggested (Ikoh \& Charles, 2005). There is need for the police to step up information gathering around suspected criminal gangs in order to discourage criminal activities and the seemingly belief among street boys that crime could bring handsome rewards. Government must understand the developmental needs of the street boys. More commitment should be given to the implementation of government's socio-economic empowerment programme. Beside this, collaboration between the government and the private sector to deliberately create employment that requires low and manual skills in the areas of Nsidung, Base Side, Idang and Etak Udari can widen the circle of economic opportunity and reduce strain induced crime. Such provisions would help in taking most of the boys from the streets and hard-to-locate hideouts, to the world of work and secure the metropolis from a marijuanalized future with its attendant hazards.

\section{REFERENCES}

Adler, F., Mueller, G.O.W \& Laufer, W.S. (1989). Criminology (2nd Eds.), New York: McGraw Hill Inc.

Agekameh, D. (2001, March, 5). Young and dangerous. Tell, 10, $22-27$.

Agnew, R. (1992). The empirical test of general strain theory. Journal of Crime and Justice, 30: 475 - 499.

Alcoholic anonymous (2005).[Online] Available: http//www.alcoholics-anonymous.org (4th March, 2008).

Blau, J. \& Blau, P. (1982). The cost of inequality: Metropolitan structure and violent crime. American Sociological Review 47, 114 - 129.

Bower, D., House, A., \& Owen, D. (2003). Understanding clinical papers. New York: John Wiley and Sons.

Cernkovich, S., Glordano, P., \& Rudolph, R. (1989). Race, Crime and the American dream. Journal of Research in Crime and Deliquency, 37, 131 - 170.

Chima, O. \& Inah, O. (2008). Land development control for sustainable growth: Case study of Henshaw and Duke Districts of Calabar. The Nation, 26.

Charles, J. O., Ikoh, M. U., Iyamba, I. E. \& Arit, O. C. (2005). Human development, child welfare and addiction: Social work perspective. Lagos: Serenity Press.

Ekpenyong, S. (1989). Social inequalities, collusion and armed robbery in Nigerian cities. British Journal of Criminology, 29 (1); $105-126$.

Ekpenyong, S. (1999).Diseased mega cities: The center of fear. A University of Port Harcourt inaugural lecture Series, No. 2.

Etim, T. I. (2000, February, 18). Youth leader dies assisting the police. Punch Newspaper, 10.

Escandon, R. \& Calvez, C. (2005). Free from addiction: In the face of drugs, AIDS and other enemies of society. Madrid: Colmenar Viejo.

Ezereonwu, J. (2001, February, 18). A nation and the youths it deserves. The Gaurdian, 19.

Ikoh, M. U. (2002). Social class and crime: The study of Agaba group in Calabar metropolis, Nigeria. An unpublished M.Sc. thesis submitted to the Department of Sociology, University of Calabar, Nigeria.

James, K. C. (1996, February). Transforming America. Imprimis, 25 (2):1- 6.

Merton, R. K. (19380. Social theory and social structure. Glencoe: The Free Press.

Noah, M. (1978). Old Calabar: The city states and the Europeans (1809 - 1885). Calabar: Scholars press.

Pasternoster, R. \& Mazerolle, P. (1994). General strain theory and delinquency: A replication and extension. Journal of Research in Crime and Delinquency, 31, $235-263$.

Sampson, R. J. (1985). Crime and public safety: Insight from community level perspective and social capital. In S. Saegert., J. p. Thompson \& M. R. warren (Eds.). Social capital and poor communities (89 - 114). New York: Russel Sage Foundation.

Short, J. \& Strodtbeck, F. L. (1974). Group processes and gang delinquency. Chicago: The University of Chicago Press.

Theo, A. (1989). Sociology: An introduction (2nd Ed.). New York: Harper and Row publishers.

Udoh, R. (1975). Migrant tenant farmers in nigeria: $A$ geography of migration in Nigeria. Lagos: Heinemann.

Zakzaky, N. (2001, October 29). Unemployed youths did the destructions. Newswatch, 34(17): 18 - 19. 